\title{
Mechanical Behavior of Treated Timber Boardwalk Decks under Cyclic Moisture Changes
}

\author{
Jian $\mathrm{LIU}^{1, \uparrow} \cdot$ Yiling $\mathrm{JI}^{1} \cdot$ Jiaming $\mathrm{LU}^{1} \cdot \mathrm{Zhi} \mathrm{LI}^{1}$
}

\begin{abstract}
Timber boardwalk decks are widely installed in parks and scenic areas to provide pedestrians an elevated footpath as well as harmony with the surrounding natural scene. In order to extend the lifespan of boardwalks in the outdoor environment, industrially treated pine timber, such as Pinus sylvestris, is often adopted. However, accidents of pedestrians injured by damaged boardwalk decks have been constantly reported. Therefore, the mechanical behavior of two different types of treated timber was examined in this study under repeated wetting and drying. An increasing number of radial cracks appeared with increasing length and width as more cycles were performed. A loss of more than $40 \%$ of the screw withdrawal capacity was observed in both end grain and face grain for the two types of timber after twelve accelerated wet-dry cycles, which coincides with the observation of damaged timber boardwalks in the field investigation. At the same time, it was found that both the compressive and the flexural strength was not sensitive to the wet-dry cycles especially at large cycle numbers.
\end{abstract}

Keywords: timber boardwalk deck, cyclic moisture change, crack, screw withdrawal, flexure, compression, microstructure

\section{INTRODUCTION}

Timber boardwalks are exposed to the rigorous outdoor environments, and timber is a material with very high sensitivity to environmental factors, including temperature, moisture, etc., which may causes cracks in timber structures without the application of any external loads (Ross, 2010). At the same time, biological intrusion, such as fungus, termite, and other insects, etc., is another threat to the safety of timber structures (Ham et al., 2021; Lee et al., 2020; Oh, 2021; Suprapti et al., 2020; Yun et al., 2021). Therefore, the material of treated timber is often preferred for timber boardwalks to increase its environmental and biological resistance. Treated timber materials include mainly the following three categories in terms of anti-corrosion characteristics: 1) natural timber materials such as western red cedar with its excellent anti-corrosion property from the alcohols constituent of Thujaplicins; 2) timber materials with a depth from the surface being carbonized under

\footnotetext{
Date Received November 6, 2021, Date Revised December 16, 2021, Date Accepted January 13, 2022

${ }^{1}$ Department of Civil Engineering, Design School, Xi'an-Jiaotong Liverpool University, Su-zhou, 215123, China

† Corresponding author: Jian LIU (e-mail: jian.liu@xjtlu.edu.cn, https://orcid.org/0000-0002-4375-043X)

(C) Copyright 2022 The Korean Society of Wood Science \& Technology. This is an Open-Access article distributed under the terms of the Creative Commons Attribution Non-Commercial License (http://creativecommons.org/licenses/by-nc/4.0/) which permits unrestricted non-commercial use, distribution, and reproduction in any medium, provided the original work is properly cited.
} 
high-temperature treatment to protect the interior from the external intrusion; 3) timber materials industrially processed with chemical preservatives, such as the preserved wood of pinus sylvestris (Ahmed et al., 2017; Lahtela and Kärki, 2016) and the treated Populus cathay (Liu et al., 2019). The key phases in this process include purging air from timber cells and impregnating the timber with protective chemicals under high pressure. Combing excellent anti-corrosion property and affordable price, two types of treated timber materials in the third category dominate the market of timber boardwalk decks in China, i.e. pinus sylvestris imported from Finland (PSF), and pinus sylvestris var mongoliaca (PSM). Due to the short illumination time in Finland, PSF has a more compact texture and fewer defects than PSM which mainly grows in the region across Siberia and the great Khingan area of China. In recent years, PSF has been recognized with higher mechanical properties than most of other species of softwood in terms of compression, shear and nail withdrawal etc. (Konofalska et al., 2021; Simsek et al., 2010)., despite its price being nearly twice as high as PSM. In this study, a field investigation was conducted at the surroundings of Jinji Lake and Dushu Lake in Suzhou, China, and it was found that most of the timber boardwalk decks were made of these two materials; however, typical problems were identified as in Fig. 1, including 1) loss of fasteners; 2) severe cracks; 3) local material corrosion. It is also common to see timber boardwalk decks replaced as short as $2-3$ years after the installation, which requires high costs of labor and finance. Otherwise, pedestrians may be injured once stepping on the damaged timber deck, which has already been reported across the country. In order to understand the mechanical behavior of timber materials, a large extent of experiments have already been carried out including nail withdrawal (Rammer et al., 2001; Taj et al., 2009), compression (Keskin, 2017; Saad et al., 2016; Xu et al., 2021), flexure (Burawska-Kupniewska et al., 2020). At the same time, it is noticed that in the region of Suzhou there is abundant rainfall as well as distinct seasons, i.e. summer with severe heat and winter with a mild cold. It is typical for outdoor infrastructures to have strong sunshine exposure followed by heavy rainwater soaking especially from early May to late October. Therefore, it is reasonable to associate the degraded mechanical behavior of timber boardwalks with the incessant wet-dry cycles. Currently, there is a large amount of research on different types of materials, e.g. soil (Artigas, 2015; Degens and Sparling, 1995; O'Connor et al., 2019), and concrete (Wang et al., 2012), under humidity cycles; however, very limited research is focused on timber (Esteban et al., 2005; Malasri et al., 2013; Yermán et al., 2021). Therefore, this study is to investigate the effect of repeated wetting and drying on two types of the most common treated timber for boardwalk decks, i.e. PSF and PSM, in terms of screw withdrawal, static compression, and static flexure, and finally to explain the reason for the short life span of timber boardwalks.

\section{MATERIALS and METHODS}

To understand the mechanical properties of timber boardwalk decks, an experimental study was carried out to investigate the screw withdrawal, static compression, and static flexure behavior under accelerated wet-dry cycles.

\subsection{Materials}

Two types of Pinus sylvestris (PS) were used in this study, i.e. PSF imported from Finland, and PSM imported from Russia or planted domestically in the great Khingan area (Fig. 1). Both PSF and PSM are processed through impregnation with a chemical agent contacting copper compounds, which renders the processed timber slightly green or blue. The main differences between PSF and PSM are 1) natural properties of the timber 


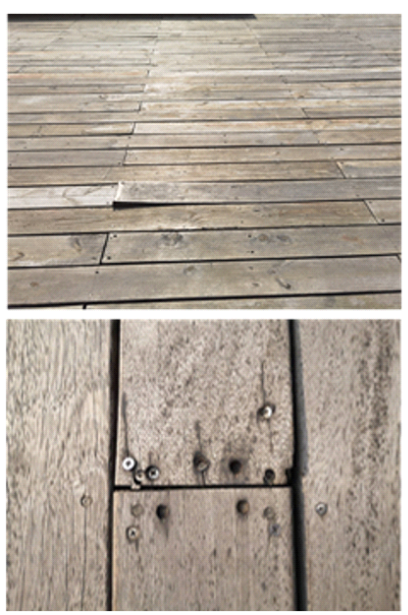

(a) Loss of nails

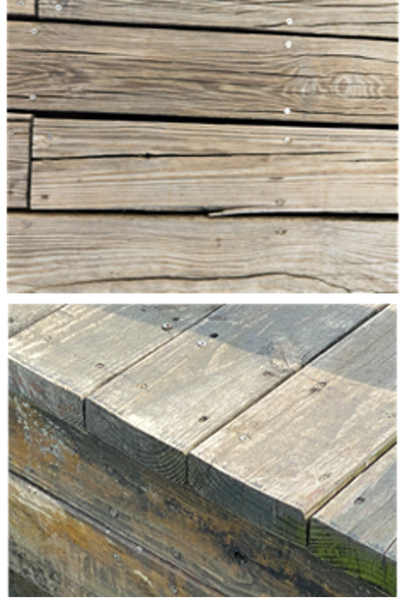

(b) Cracks

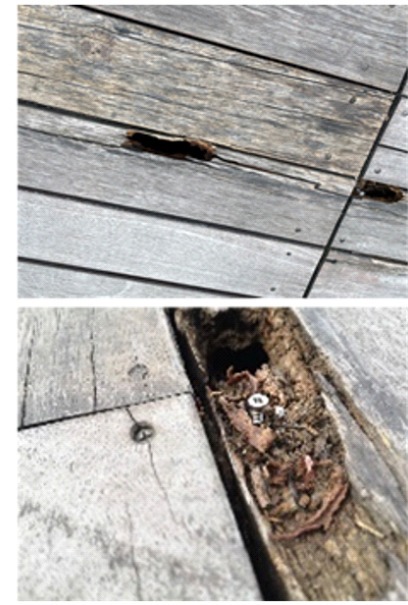

(c) Material decay

Fig. 1. Typical problems observed in timber boardwalks.

species; 2) anti-corrosion processing standards. As shown in Fig. 2, annual rings are denser in PSF due to their slow growth speed, which makes the timber material harder with fewer defects and less resin. At the same time, qualified PSF must undergo a second drying process after the impregnation which guarantees a high permeation rate of preservative solution into the timber materials.

\subsection{Environmental condition}

Since this study originated in Suzhou, China, the local climatic condition is studied based on the historical record. Fig. 3 shows the weather history in January and July in the year 2020 by indicating the sunny (8-17 h) and rainy $(0-24 \mathrm{~h})$ days in the entire month. It can be seen that during January the direct sun exposure and rain soaking lasted for approximately 70.5 hours and 199.5 hours, respectively; while in July these values varied to 91 hours and 101 hours, respectively. Outdoor timber structures are extremely susceptible to the contrast between rainwater impregnation and sunlight irradiation to their surfaces, which causes fast evolution of moisture content, and eventually significant loss of mechanical

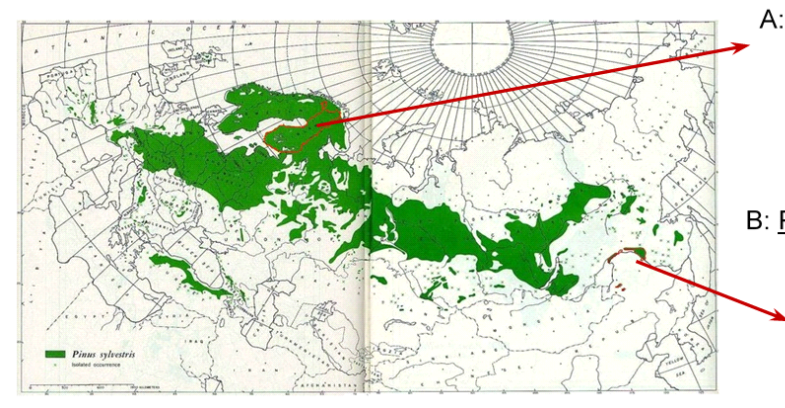

A: Pinus sylvestris from Finland (PSF)

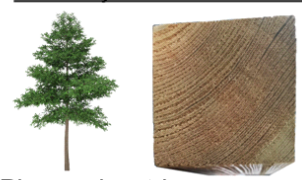

B: Pinus sylvestris var. mongolica (PSM)

Fig. 2. Two types of impregnated timber studied in this paper. 
capacities. Besides, the relative air humidity (RAH) also has a significant effect on the preservation of timber products, and its evolution is also shown in Fig. 3, which remained high during the entire year, i.e. with average $=78 \%$ in winter and $83 \%$ in summer. At the same time, the RAH exhibited a high frequency of variation, e.g. underwent more than 15 cycles of between $100 \%$ and approximately $50 \%$ in January and even more cycles in July. The hygro-thermal variation of timber boardwalk is even more prominent at the lakeside due to the evaporation and level rising of lake water. According to the Chinese Standard GB/T 50329-2012 (Chinese Standard, 2012), the annual average equilibrium moisture content (EMC) for timber product is approxi- mately $16 \%$ in the area of Shanghai, which is $100 \mathrm{~km}$ to the east of Suzhou. To reflect the level of moisture change an index named "Scheffer Climate Index (SCI)" (Scheffer, 1971) is usually used to quantify the weather condition according to the monthly temperature and days with measurable rainfall $(>0.25 \mathrm{~mm})$. It was found that untreated timber decks were prone to decay faster under higher SCI which means more rainfall and higher temperature. However, it is impossible to provide this index for Suzhou in this study due to the lack of daily rainfall record. Therefore, accelerated wet-dry cycles were used to simulate the aforementioned rain-sunlight contrast qualitatively, where the timber samples were soaked in water for at least 21 hours and then dried in

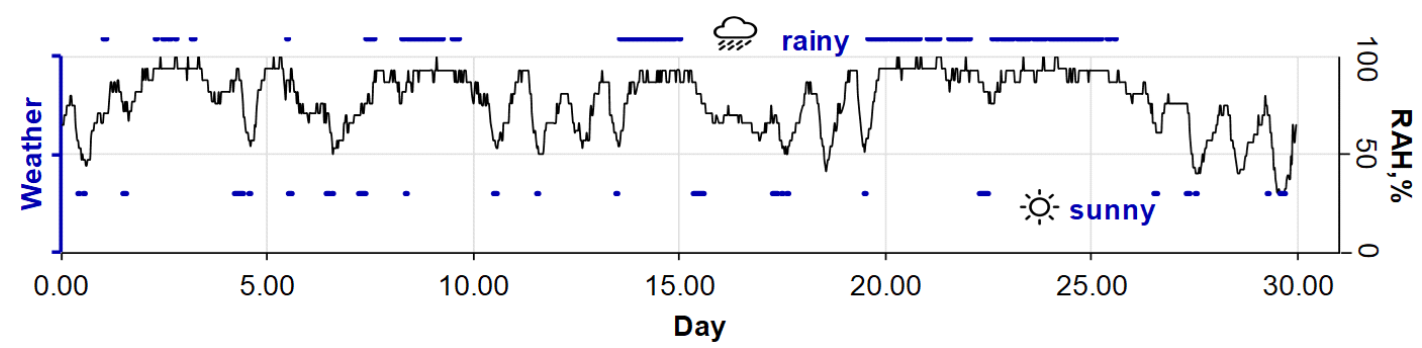

(a) Local weather condition recorded in January 2020 (Avg. Temperature $3^{\circ} \mathrm{C}-9^{\circ} \mathrm{C}$ )

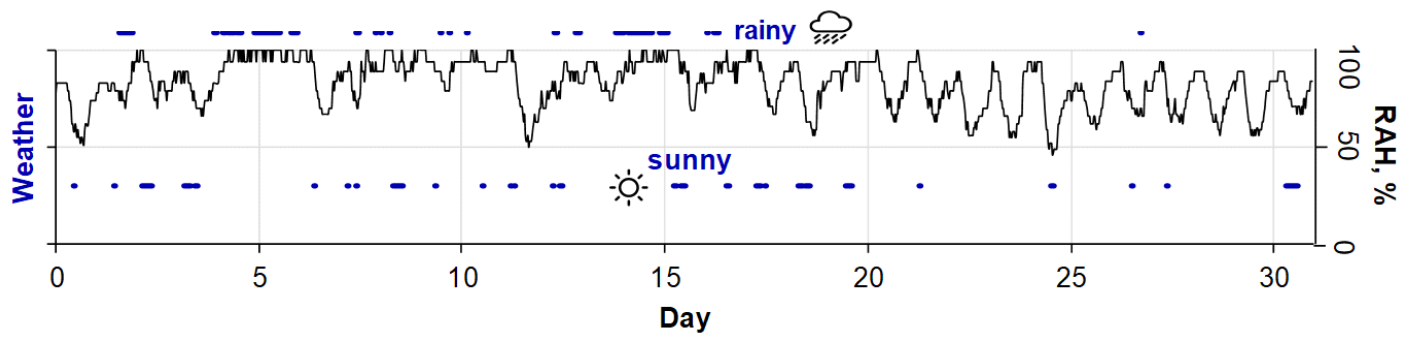

(b) Local weather condition recorded in July 2020 (Avg. Temperature $25^{\circ} \mathrm{C}-32^{\circ} \mathrm{C}$ )

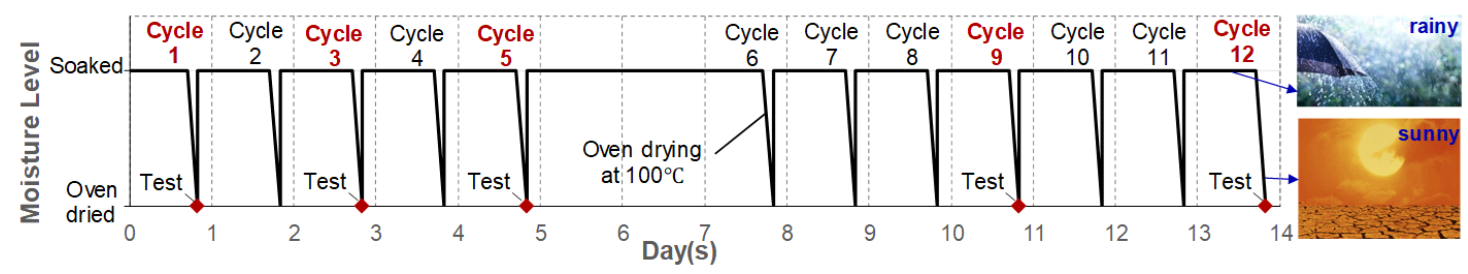

(c) Accelerated wet-dry cycles

Fig. 3. Environmental condition. 
an electric oven for 3 hours at $103^{\circ} \mathrm{C}$ in each cycle as shown in Fig. 3(c). In total 12 cycles were repeated in this study, and mechanical tests were performed at the end of Cycle 1, 3, 5, 9, and 12 including screw withdrawal, compression, and flexure tests. Before each test, the moisture content was measured for each specimen which ranged from $10 \%-18 \%$. Although the conditions of the accelerated wet-dry seem harsh, the temperature at timber surface during sun peak hours in summer can reach as high as $60^{\circ} \mathrm{C}$ according to studies carried out in Seoul (Lee et al., 2018) which is located at higher latitude than Suzhou. Although in this study the water content in timber specimen evaporated at $103^{\circ} \mathrm{C}$ rather than diffusing at $60^{\circ} \mathrm{C}$ into the dry air, there was almost no damage to the microstructure of the timber specimen according to a test performed at $120^{\circ} \mathrm{C}$ by other researchers (Korkut et al., 2008). In addition, the sunlight spectrum includes a small portion of Ultraviolet (UV) light, which may cause damage to the microstructure and accelerate the aging of timber material (Kim and Kim, 2021). The effect of UV light is not considered in this study.

\subsection{Mechanical tests}

In order to find out the screw withdrawal capacity of PSF and PSM under the aforementioned accelerated wet-dry cycles, a series of tests were carried out according to the current Chinese testing standards of timber materials (Chninese Standard, 2009a, 2009b, 2009c) as shown in Fig. 4(a). Six specimens with the size of 50 $\mathrm{mm} \times 50 \mathrm{~mm} \times 150 \mathrm{~mm}$ were prepared for each material type, i.e. PSF and PSM, with the grain following the direction of long side. $4.5 \mathrm{~cm}$ long stainless steel screws with a diameter of $4 \mathrm{~mm}$ were drilled into the timber specimens at three positions labeled as 'Screw-1',

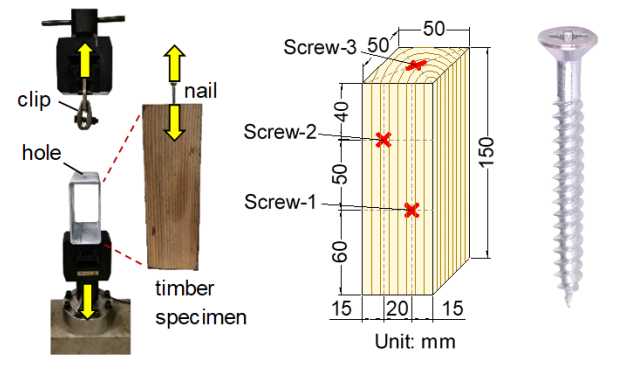

(a) Screw withdrawal test

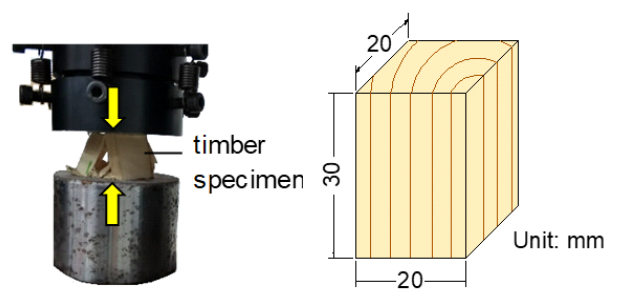

(b) Compression test

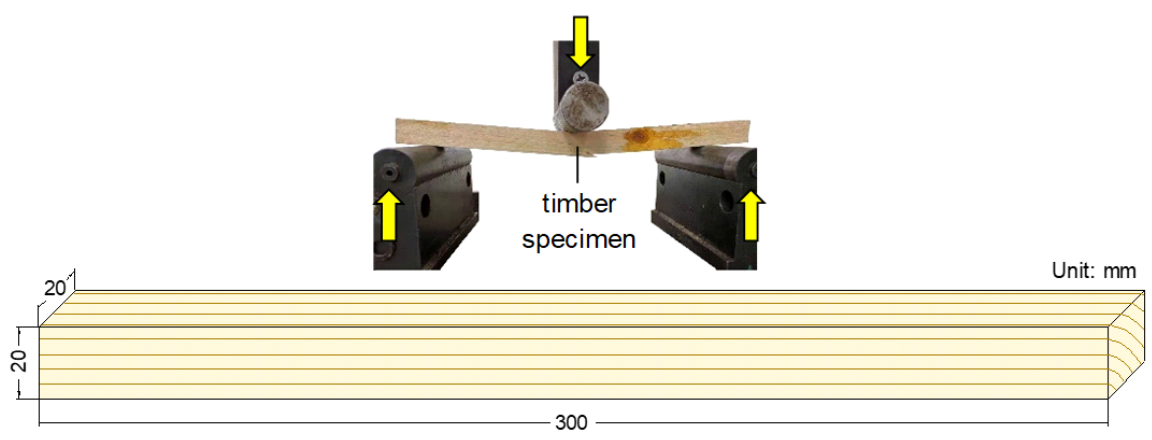

(c) Flexural test

Fig. 4. Experiment setup. 
'Screw-2' and 'Screw-3' in Fig. 4. Screws-1 and 2 are perpendicular to the grain while Screw-3 is parallel to the grains. A simple apparatus was set up to pull out the screws from the timber specimens through a clip, and the vertical load was applied by hydraulic elongator. Five samples of $20 \mathrm{~mm} \times 20 \mathrm{~mm} \times 30 \mathrm{~mm}$ were prepared for PSF and PSM, respectively. Vertical compressive forces were applied along the grain direction with the help of a hydraulic actuator as shown in Fig. 4(b). The three-point bending test setup is shown in Fig. 4(c), five scaled timber beam specimens with a span of $300 \mathrm{~mm}$ and a cross-section of $20 \mathrm{~mm} \times 20 \mathrm{~mm}$ was prepared of PSF and PSM, respectively. The aforementioned information is summarized in Table 1. All the specimens were sawn from commercial treated PSM and PSF purchased at qualified suppliers.

\section{RESULTS and DISCUSSION}

The experimental results are discussed in this section in terms of cracks, screw withdrawal capacity, compressive as well as flexural capacity.

\subsection{Cracks}

As observed in the experiment, cracks appear in all sizes of timber specimens of both PSF and PSM with an increasing number of wet-dry cycles, which is due to the uneven dimensional changes caused by the repeated swelling and shrinking. While limited cracks appear along the grain direction, the increase of radial cracks is prominent in terms of both number and size as shown in Fig. 5. At Cycle 1 almost no radial cracks can be seen with naked eyes, and more than 20 cracks of different sizes can easily be identified after Cycle 9. There were even tangential cracks observed between earlywood and latewood after Cycle 12, and the maximum crack reached as wide as $0.6 \mathrm{~mm}$. The fast development of cracks is very crucial to the safety of timber boardwalk decks which allows rainwater to enter the interior of timber materials to increase the decay speed, and eventually will shorten the lifespan of timber boardwalks. A slight larger number of cracks appeared in specimens of PSM than PSM.

\subsection{Screw withdrawal behaviour}

Screws were pulled out from the timber specimens following the testing procedure discussed in Section 2. The typical failure mode of Screws-1 and 2 perpendicular to the grain direction (Fig. 4(a)) under increasing wet-dry cycles is shown in Fig. 6. It can be seen that as the screw was pulled out, the fiber surrounding the screw was peeled out and the splitting propagated to a certain distance along the grain direction, which was also observed by other researchers (Brown et al., 2020; Matsubara et al., 2017). As the specimen underwent more wet-dry cycles, a larger area of fiber was affected around the perimeter of the screw. There was almost no peeling out of fibers identified at the location of Screw-3 which aligned along the grain direction. Similar observations were made for both PSF and PSM.

Table 1. Information of specimens

\begin{tabular}{cccc}
\hline Mechanical test & Size of specimens & No. of specimens & No. of repetition \\
\hline \hline Nail withdrawal & $50 \mathrm{~mm} \times 50 \mathrm{~mm} \times 150 \mathrm{~mm}$ & 6 (PSF); 6 (PSM) & 1 (some are repeated) \\
Compression & $20 \mathrm{~mm} \times 20 \mathrm{~mm} \times 30 \mathrm{~mm}$ & 5 (PSF); 5 (PSM) & 2 \\
Bending & $20 \mathrm{~mm} \times 20 \mathrm{~mm} \times 300 \mathrm{~mm}$ & 5 (PSF); 5 (PSM) & 2 \\
\hline
\end{tabular}

PSM: Pinus sylvestris var. mongoliaca. 

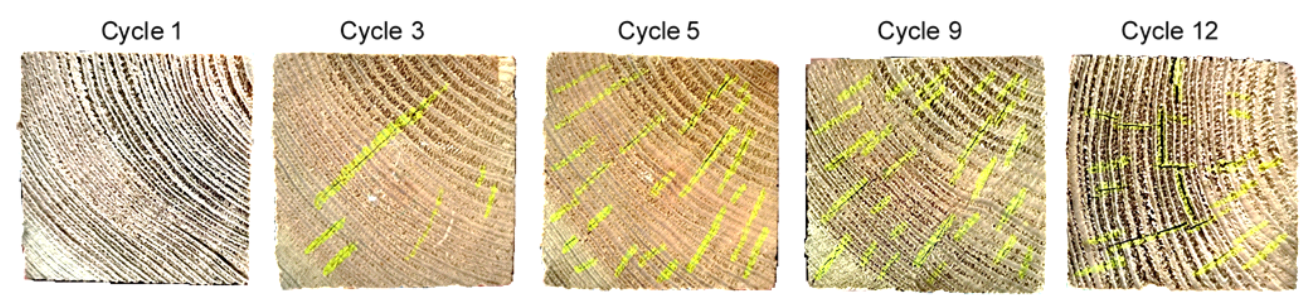

(a) Crack distribution at end grain of PSF

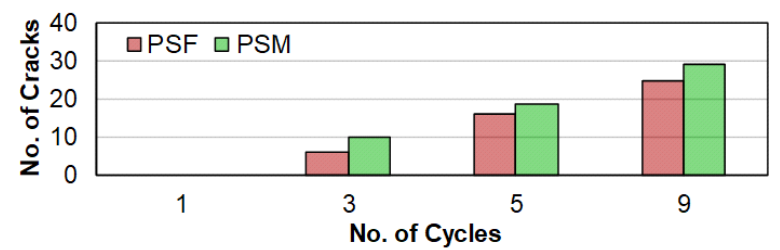

(b) Number of cracks at end grain

Fig. 5. Increasing of radial cracks with wet-dry cycles. PSF: Pinus sylvestris imported from Finland.
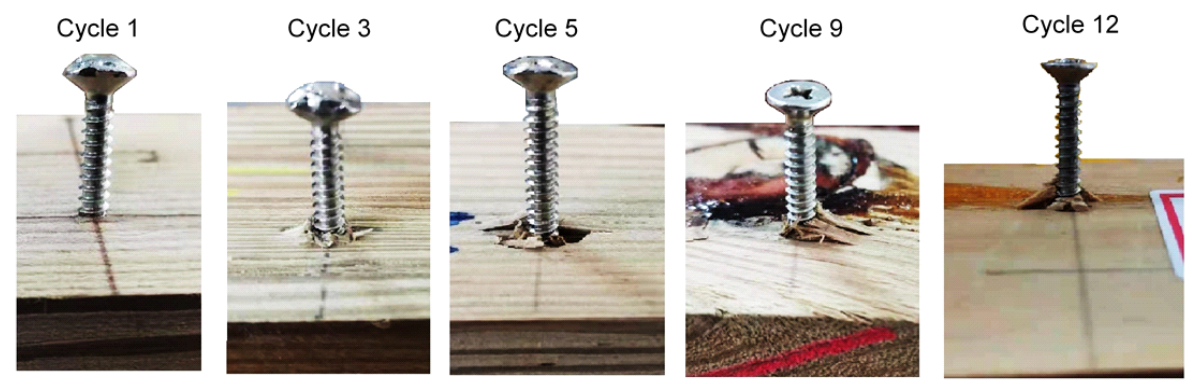

Fig. 6. Failure mode of screw withdrawal with wet-dry cycles.

The pulling force-displacement relationship of screws in PSF specimens can be seen in Fig. 7. It is interesting to notice that after the initial loading stage there was a significant drop of stiffness where the pulling of the screw was proceeded without applying any extra forces. However, the stiffness picked up rapidly after the displacement reached nearly $50 \%$ of the displacement at withdrawal failure. Rather than decreasing constantly with wet-dry cycles, it appeared that the screw withdrawal capacity was strengthened in the first 3 cycles and a drop of approximately $40 \%$ in Cycle 5 . Slow decreases were observed afterward for both screw withdrawal capacity and displacement from Cycle 5 to Cycle 12. In terms of different screw positions, screws perpendicular to longitudinal grains (1\&2 in Fig. 4(a)) possess more than twice withdrawal capacities than the one in parallel with grains, i.e. Screw-3. This can be explained by the hindering effect of different timber layers separated by annual rings, and each layer provides resistance through splitting for Screws 1 and 2 as shown in the right plot of Fig. 7.

The screw withdrawal capacity for both material types, i.e. PSF and PSM are demonstrated in Fig. 8. Similar trends were observed as above, i.e. the screw withdrawal 

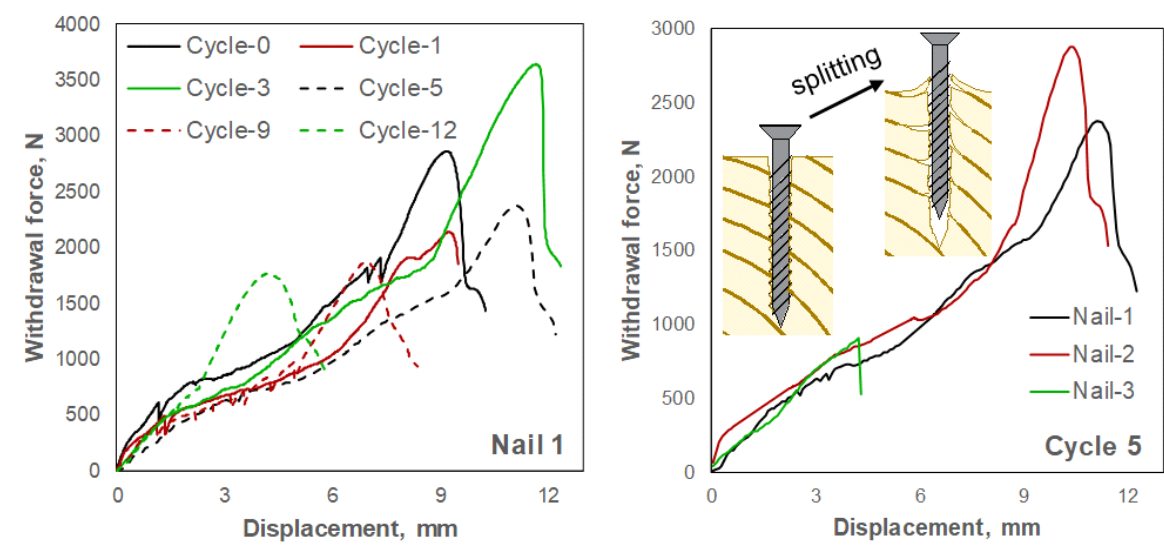

Fig. 7. Variation of screw withdrawal response with wet-dry cycles.
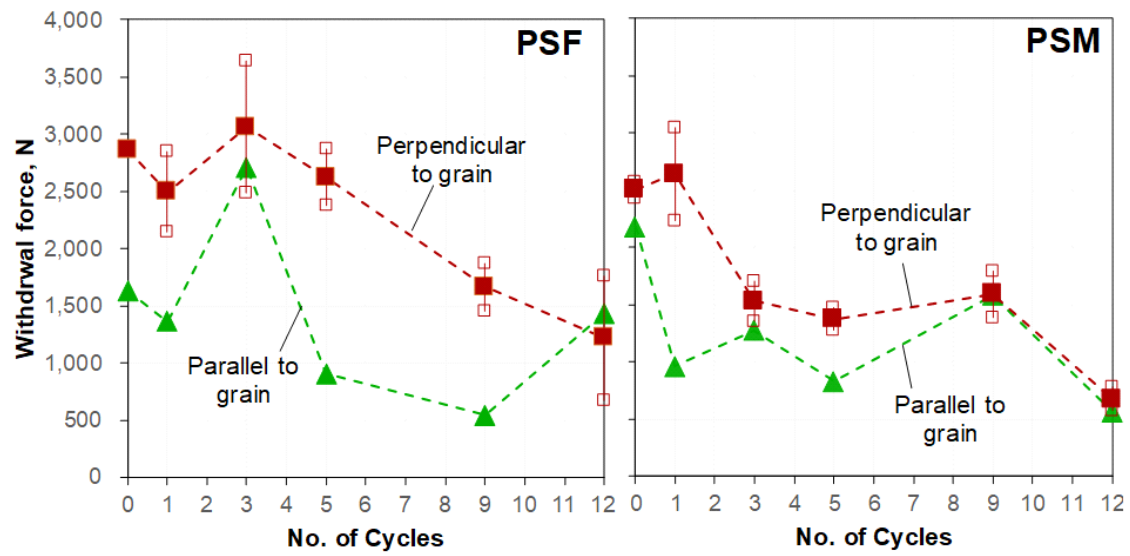

Fig. 8. Variation of screw withdrawal capacity with wet-dry cycles. PSF: Pinus sylvestris imported from Finland, PSM: Pinus sylvestris var. mongoliaca.

capacity did not undergo a prominent decrease until after 2-3 wet-dry cycles. At Cycle 9, the residual capacity dropped to approximately half of the original strength. Generally speaking, the screw withdrawal capacity for PSF was slightly higher than PSM at the initial state, and a more rapid decrease was shown for PSF which resulted in a similar capacity level in both materials at Cycle 12. The prominent effect of wet-dry cycles on the screw withdrawal behavior is also due to the fact that the screw penetration depth is small com- pared with the specimen size, where the cell wall of tracheids (see details in 3.5) is more susceptible to volumetric changes.

\subsection{Compressive behavior}

The compressive behavior of PSF and PSM was examined in this study. The results were shown in Fig. 9, which indicates that the compressive strength was enhanced after wet-dry cycles were implemented. At 

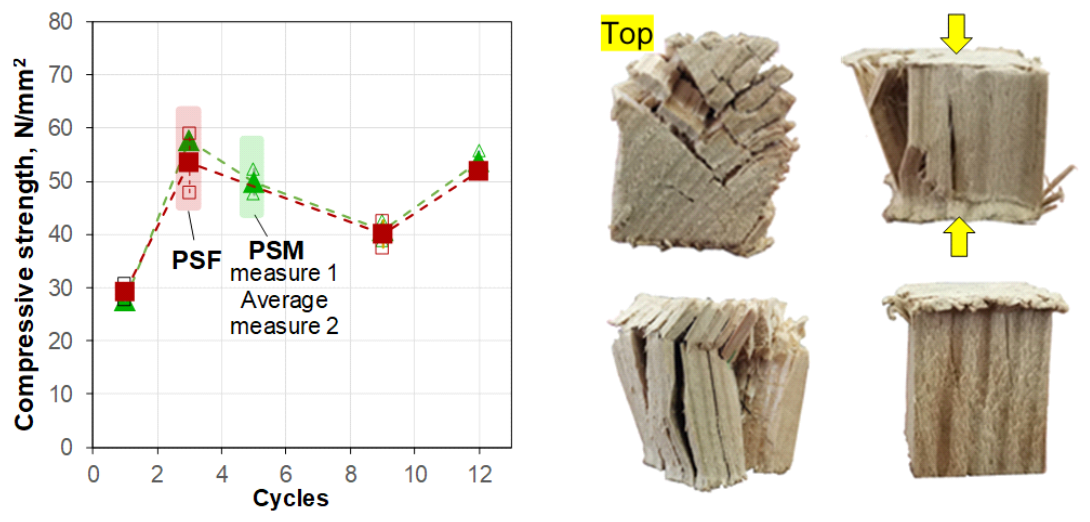

Fig. 9. Variation of compressive capacity with wet-dry cycles.

Cycle 3 the compressive strength almost doubled compared with Cycle 1, and afterward the strength did not vary significantly. Besides, the compressive strength of both materials was almost identical under different numbers of cycles. The possible explanation of this counterintuitive phenomenon is the following: the parallel strands of cellulose fibers bonded by lignin align with the direction of compression, and the lateral expansion due to Poisson effect weakens the bond between fibers even without any wet-cycle cycles; at the same time, radial and tangential cracks observed under wet-dry cycles also cause weaker bond between fibers, but this effect is minor compared with that due to lateral expansion. Typical failure modes were listed in Fig. 8. Originally the specimen failed locally at the perimeter of the surfaces facing the loading machine. As observed earlier in this study more cracks appeared in the timber specimens, which caused the compact specimen into several parts separated by radial and tangential cracks according to annual rings in the longitudinal grain direction. Eventually, instead of local failure, the specimen failed in a manner as the buckling of those individual "columns" separated by cracks. Similar failure mode was observed by other researchers in both experimental and numerical analysis of axial compression process of wood microstructure (Zhong et al., 2015). In addition, no obvious difference was observed between PSF and PSM in terms of both failure mode and strength under compression.

\subsection{Flexural behaviour}

Scaled beams with a length of $300 \mathrm{~mm}$ were tested in this study. The typical failure modes are shown in Fig. 10. Compared with specimens of other tests, the beams had larger geometric sizes which brought the defects in timber materials into attention. When there was no defect, cracks appeared at the bottom fibers at the mid-span of the beams where the bending moments are the maximum and slowly propagated towards top fibers. However, if there were defects (mainly knots), cracks may originate there as Fig. 10(c). At the same time, the cross-sectional distribution of end grains is different among the specimens as shown in Fig. 10(d), which causes different angles between end radial cracks and bending axis.

Despite that natural defects, which are unavoidable in timber materials, may reduce the mechanical strength of timber specimens (As et al., 2006), the effect of wet-dry cycles had little effect on the flexural behavior of both PSF and PSM in terms of both strength and displacement. At Cycle 5 the measured flexural capacity was 1.08 and 0.99 times of the original strength for PSF and 


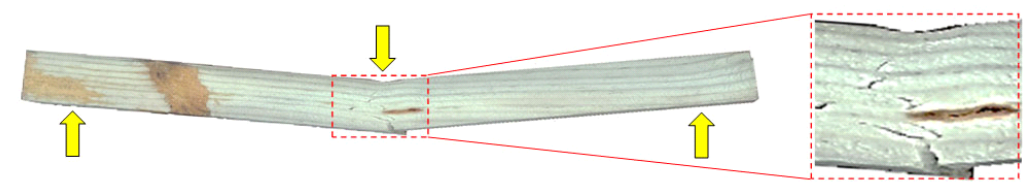

(a) Side view

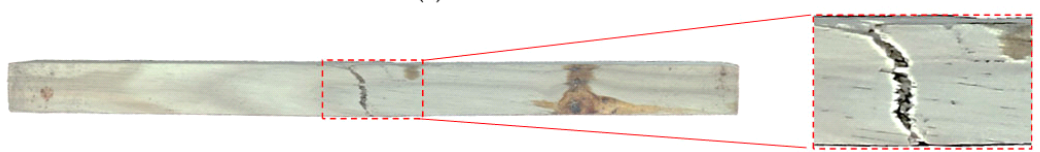

(b) Bottom view
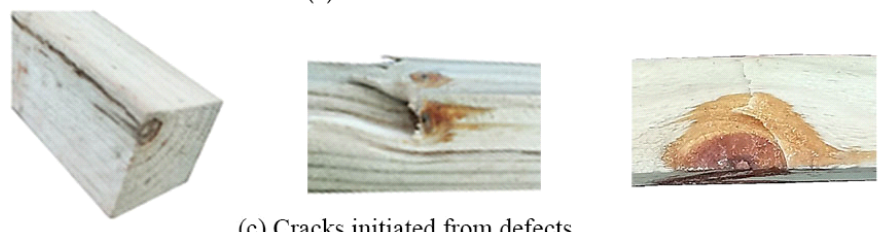

(c) Cracks initiated from defects

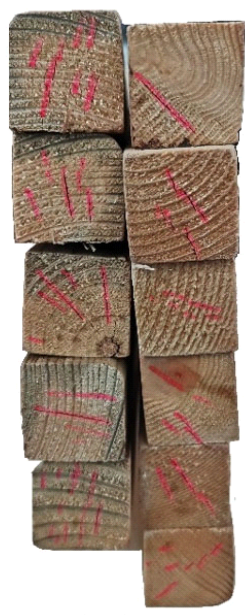

(d) Radial cracks

Fig. 10. Typical flexural failure mode.

PSM, respectively. This is because the orientation of the cracks induced by wet-dry cycles are mainly radial and tangential without any transverse observed, which may slightly affect the bond between fibers and result in weakened bending strength, but the cracks are mostly located close to surface which has minor effect on the mid-span section sustaining the maximum bending moment. The deflection of timber specimens at maximum bending moment was also recorded, and a decrease of $30 \%-50 \%$ can be observed at Cycle 12 . This phenomenon might be also related to the volumetric change caused by wet-dry cycles through uneven deformation among different layers of cell wall. Overall, the flexural strength of PSF is approximately $30 \%$ higher than PSM as shown in Fig. 11.

\section{CONCLUSION}

In this study, the mechanical properties including screw withdrawal, compression, and bending behaviors under wet-dry cycles were examined through laboratory tests. The following conclusions can be made:

Severe radial and tangential cracks according to the annual rings were observed as more wet-dry cycles were implemented, and limited longitudinal cracks were induced;

The effect of wet-dry cycles was negligible on screw withdrawal capacity when only a small number of cycles were performed; however, significant regression can be seen with increasing cycles. At Cycle 12, the screw withdrawal capacity was as low as $40 \%-50 \%$ of the original capacity, which may cause loss of screws in timber boardwalk decks and eventually structural damage;

The compressive capacity of both PSF and PSM specimens was strengthened in the first few wet-dry cycles and kept stable as more cycles were performed. The failure mode shifted from the local failure of compact timber specimens to "structural buckling"-like of cracked specimens, which might be the reason for enhanced compressive strength;

The flexural strength was not obviously affected by wet-dry cycles, but it was noted that as the size of timber structures increases more defects might be encountered and result in immature structural failure initiating from the defects, and therefore the size effect of 

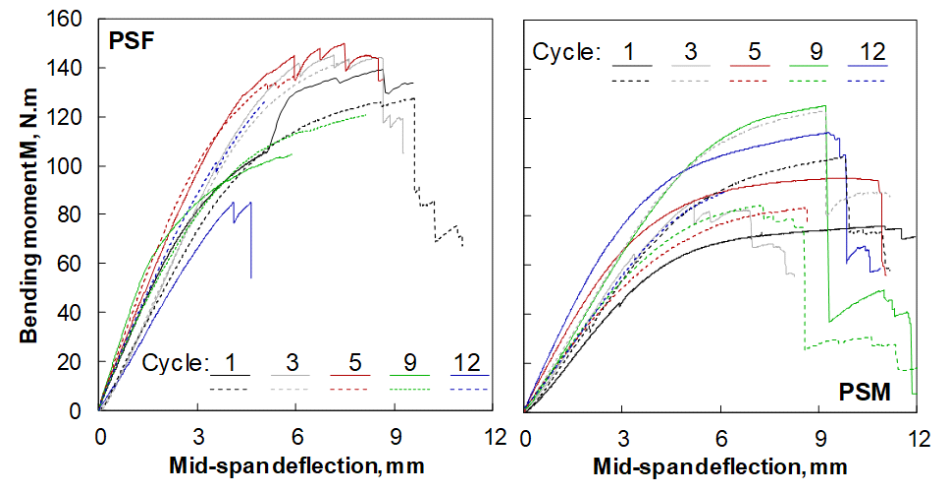

(a) Flexural response of PSF/PSM specimens

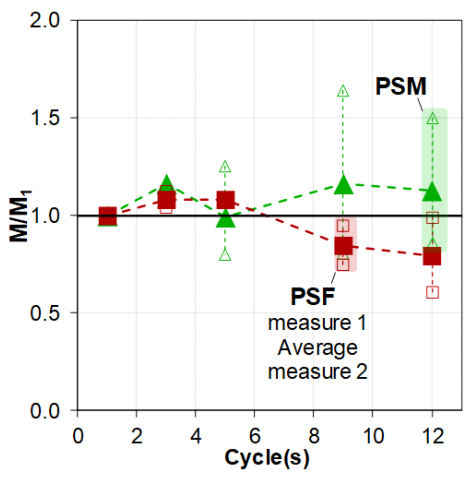

(b) Variation of flexural capacity

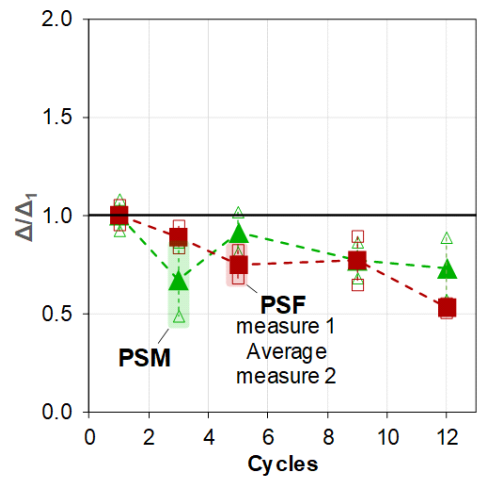

(c) Variation of deflection

Fig. 11. Variation of flexural response with wet-dry cycle. PSF: Pinus sylvestris imported from Finland, PSM: Pinus sylvestris var. mongoliaca.

timber structures might be also an interesting research topic in the future;

Based on both the filed investigation and laboratory tests, the most crucial reason for the short lifespan of treated timber boardwalk decks at lakeside is their decaying nail/screw withdrawal capacity under a similar climate condition as in Suzhou. Therefore, more attention should be paid to the choice, installation and treatment of fasteners for treated timber boardwalk decks in engineering practice.

\section{CONFLICT of INTEREST}

No potential conflict of interest relevant to this article was reported.

\section{ACKNOWLEDGMENT}

Not applicable.

\section{REFERENCES}

Ahmed, S.A., Morén, T., Sehlstedt-Persson, M., Blom, A. 2017. Effect of oil impregnation on water repellency, dimensional stability and mold susceptibility of thermally modified European aspen and downy birch wood. Journal of Wood Science 63(1): 74-82. Artigas, A., Monsalve, A., Sipos, K., Bustos, O., Mena, 
J., Seco, R., Garza-Montes-de-Oca, N. 2015. Development of accelerated wet-dry cycle corrosion test in marine environment for weathering steels. Corrosion Engineering, Science and Technology 50(8): 628-632.

As, N., Goker, Y., Dundar, T. 2006. Effect of knots on the physical and mechanical properties of scots pine. Wood Research 51(3): 51-58.

Brown, J., Li, M., Karalus, B., Stanton, S. 2020. Withdrawal behaviour of self-tapping screws in New Zealand cross-laminated timber. New Zealand Timber Design Journal 28(2): 25-32.

Burawska-Kupniewska, I., Krzosek, S., Mańkowski, P., Grześkiewicz, M. 2020. Quality and bending properties of Scots pine (Pinus sylvestris L.) sawn timber. Forests 11(11): 1200.

Chinese Standard (2009a). GB/T 14018-2009: Method of Testing Nail Holding Power of Wood. China Building Industry Press, Beijing, China.

Chinese Standard (2009b). GB/T 1935-2009: Method of Testing in Compressive Strength Parallel to Grain of Wood. China Building Industry Press, Beijing, China.

Chinese Standard (2009c). GB/T 1936.1-2009: Method of Testing in Bending Strength of Wood. China Building Industry Press, Beijing, China.

Chinese Standard (2012) GB/T 50329-2012: Standard for Test Methods of timber Structures. China Building Industry Press, Beijing, China.

Degens, B.P., Sparling, G.P. 1995. Repeated wet-dry cycles do not accelerate the mineralization of organic $\mathrm{C}$ involved in the macro-aggregation of a sandy loam soil. Plant and Soil 175(2): 197-203.

Esteban, L.G., Gril, J., de Palacios, P.P., Casasús, A.G. 2005. Reduction of wood hygroscopicity and associated dimensional response by repeated humidity cycles. Annals of Forest Science 62(3): 275-284.

Ham, Y., An, J., Lee, S.M., Chung, S., Kim, S.H., Park, M. 2021. Isolation and identification of fungi asso- ciated with decay of Quercus mongolica. Journal of the Korean Wood Science and Technology 49(3): 234-253.

Kim, J.Y., Kim, B.R. 2021. Hygroscopicity and ultraviolet (UV) deterioration characteristics of finished woods. Journal of the Korean Wood Science and Technology 49(5): 471-481.

Keskin, H. 2017. Effects of impregnation with Tanalith-E on the compression strength of some woods. Politeknik Dergisi 20(3): 711-716.

Konofalska, E., Kozakiewicz, P., Buraczyk, W., Szeligowski, H., Lachowicz, H. 2021. The technical quality of the wood of Scots pine (Pinus sylvestris L.) of diverse genetic origin. Forests 12(5): 619.

Korkut, S., Akgül, M., Dündar, T. 2008. The effects of heat treatment on some technological properties of Scots pine (Pinus sylvestris L.) wood. Bioresource Technology 99(6): 1861-1868.

Lahtela, V., Kärki, T. 2016. Effects of impregnation and heat treatment on the physical and mechanical properties of Scots pine (Pinus sylvestris) wood. Wood Material Science \& Engineering 11(4): 217-227.

Lee, J.M., Kim, Y.H., Hong, J.Y., Lim, B., Park, J.H. 2020. Exploration of preservatives that inhibit wood feeding by inhibiting termite intestinal enzyme activity. Journal of the Korean Wood Science and Technology 48(3): 376-392.

Lee, S., Moon, H., Choi, Y., Yoon, D.K. 2018. Analyzing thermal characteristics of urban streets using a thermal imaging camera: A case study on commercial streets in Seoul, Korea. Sustainability 10(2): 519.

Liu, J., Liu, M., Hou, B., Ma, E. 2019. Decay of Populus cathay treated with paraffin wax emulsion and copper azole compound. Journal of the Korean Wood Science and Technology 47(1): 21-32.

Malasri, S., Harvey, M., Moats, R., Aflaki, J., Pourhashemi, A., Martinez, G.M., Held, P. 2013. Effect of wet-dry cycles on compressive strength and impact properties of new softwood pallets. 
International Journal of Advanced Packaging Technology 1(1): 15-21.

Matsubara, D., Wakashima, Y., Fujisawa, Y., Shimizu, H., Kitamori, A., Ishikawa, K. 2017. Relationship between clamp force and pull-out strength in lag screw timber joints. Journal of Wood Science 63(6): 625-634.

O'Connor, D., Pan, S., Shen, Z., Song, Y., Jin, Y., Wu, W.M., Hou, D. 2019. Microplastics undergo accelerated vertical migration in sand soil due to small size and wet-dry cycles. Environmental Pollution 249: 527-534.

Oh, S.C. 2021. Residual strength estimation of decayed wood by insect damage through in situ screw withdrawal strength and compression parallel to the grain related to density. Journal of the Korean Wood Science and Technology 49(6): 541-549.

Rammer, D.R., Winistorfer, S.G., Bender, D.A. 2001. Withdrawal strength of threaded nails. Journal of Structural Engineering 127(4): 442-449.

Ross, R.J. 2010. Mechanical Properties of Wood. In: Wood Handbook: Wood as an Engineering Material. USDA Forest Service, Madison, WI, USA, General Technical Report FPL-GTR-190.

Saad, S., Kobori, H., Kojima, Y., Suzuki, S. 2016. Performance evaluation of wood-based panels under a mild accelerated aging treatment. Journal of Wood Science 62(4): 324-331.

Scheffer, T.C. 1971. A climate index for estimating potential for decay in wood structures above ground. Forest Products Journal 21(10): 25-31.

Simsek, H., Baysal, E., Peker, H. 2010. Some mechanical properties and decay resistance of wood impregnated with environmentally-friendly borates.
Construction and Building Materials 24(11): 22792284.

Suprapti, S., Djarwanto, D., Dewi, L.M. 2020. Determining the wood (Parashorea spp.) decaying and metal corroding abilities of eight fungi. Journal of the Korean Wood Science and Technology 48(1): 50-60.

Taj, M.A., Najafi, S.K., Ebrahimi, G. 2009. Withdrawal and lateral resistance of wood screw in beech, hornbeam and poplar. European Journal of Wood and Wood Products 67(2): 135-140.

Wang, H., Dong, Y.S., Sun, X., Jin, W. 2012. Damage mechanism of concrete deteriorated by sulfate attack in wet-dry cycle environment. Journal of Zhejiang University (Engineering Science) 46(7): 1255-1261.

Xu, J., Zhang, S., Wu, G., Gong, Y., Ren, H. 2021. Withdrawal properties of self-tapping screws in Japanese larch (Larix kaempferi (Lamb.) Carr.) cross-laminated timber. Forests 12(5): 524.

Yermán, L., Ottenhaus, L.M., Montoya, C., Morrell, J.J. 2021. Effect of repeated wetting and drying on withdrawal capacity and corrosion of nails in treated and untreated timber. Construction and Building Materials 284: 122878.

Yun, J., Shin, H.C., Hwang, W.J., Yoon, S.M., Kim, Y.S. 2021. Identification of Sapstain fungi on weathered wooden surfaces of buildings at Jangheung and Jeju Island. Journal of the Korean Wood Science and Technology 49(6): 591-601.

Zhong, W., Rusinek, A., Jankowiak, T., Huang, X., Farid, A.B.E.D. 2015. Experimental and numerical investigation on compression orthotropic properties of spruce wood in axial and transverse loading directions. Engineering Transactions 62(4): 381-401. 